\title{
The Research on Supplier Selection Model of the Third Party Logistics Based on Grey Clustering
}

\author{
Yewang Zhou
}

\begin{abstract}
Supplier selection of the third party logistics play a very important role in supply chain management, which determine the whole competitive power of supply chain directly, selecting a suitable supplier of the third party logistics become an important component of the modern enterprise strategy. The paper has introduced the index of the third party logistics supplier evaluation at first, then has introduced the existing supplier selection method, point out the disadvantage of different methods, propose supplier selection model of the third party logistics on the basis of gray clustering and multi-objective decision-making with entropy weight, thus get the best supplier. At last set a simple example to explain the validity of the method, which can solve finely the problem of supplier selection of the third party logistics.
\end{abstract}

Index Terms-Supplier selection, model, grey clustering, entropy weight.

\section{INTRODUCTION}

Enterprises should concentrate their attention on one's own key business in nowadays fierce international competition, utilize outside resource to outsource non-core business at the same time [1]. The main business is logistics business in the outsourcing business, logistics as the important component of supply chain plays an important role in whole efficiency and cost of supply chain. Logistics certainly will influence enterprises development as "the third profit source" of enterprises. So enterprise should utilize fully the third party logistics resource which can reduce logistics cost and can also get the channel resource and information technical support of third party logistics [2]. But because logistics outsourcing is a enterprise strategic issue, the third party logistics need establish a kind of long-term and strategic partnership with enterprise. So it is necessary for enterprises to set up a suitable logistics supplier selection index system and method to help enterprises to select and evaluate potential the third party logistics. This paper put forward the third party logistics supplier selection model on the basis of grey clustering and multi-objective decision-making with entropy weight, which can offer help for enterprise to select the third party logistics supplier scientifically and rationally.

\section{The ThiRd PARTy LOGISTICS SUPPlier SELECTION INDEX AND METHOD}

\section{A. Selection Index}

Generally speaking, the third party logistics supplier

Manuscript received June 23, 2014; revised August 26, 2014.

Yewang Zhou is with the School of Business, Huanggang Normal University, Huanggang, 43800, China (e-mail: whuw@sina.com). selection mainly includes four great respects index: service price, service quality, service ability, hardware index.

Service price includes: fixed price, discount price, market floating price.

Service quality include: punctuation rate, the rate of accuracy, the proportion in good condition, etc.

Service ability includes: convenience, flexibility, informationization, etc.

Hardware index include: experience, scale, logistics facilities, etc.

The third party logistics supplier selection is a first choice to the supplier frequently, and have not business contact with this supplier before choosing the supplier, so many index got when enterprise evaluate the supplier are qualitative, there are few quantitative index, this increases uncertainty when selecting a supplier for us, because of this we must find one suitable evaluation method of the third party logistics supplier selection.

\section{B. The Third Party Logistics Supplier Selection Method}

The method of supplier selection is mainly divided into 3 kinds at present [3], [4].

The first kind is qualitative analytic approach ,the analytic approach when evaluating the supplier mainly according to past experience and past relation, for example, intuitive judgment principle, biding method etc., this kind of subjective judgement is often not accurate enough, especially when the supplier's condition is closely, can't distinguish the supplier;

The second kind is quantitative analytic method .for example, costing method, DEA method. Costing method is after considering the supplier's product quality and delivery date, have only considered an index ignores other very important indexes such as the cost, not very overall in appraisal to the supplier. The shortcoming of DEA method can't further distinguish the effective supplier well and badly, through meticulous choice in weight, make one who have advantage in little index but have inferior position in more index becomes to be relatively effective supplier.

The third method is a mix of qualitative analytic approach and quantitative analytic approach. For instance the Analytic Hierarchy process, fuzzy comprehensive evaluation, neural network algorithm, etc... Though these methods are often adopted in reality, but some computational processes of these methods are very complicated, and the problem of selecting the index weight exists also.

Enterprises select the third party logistics supplier is a complicated dynamic multifactor comprehensive decision question, the message that the policymaker receives is incomplete, is grey information. So applying grey systematic theory for selecting the third party logistics supplier and solving the problem is a suitable method [5], [6]. 
The first step of the third party logistics supplier selection is that roughly evaluating and screening among numerous suppliers, then divide into three kinds generally, strategic supplier, alternative supplier, and non-qualified supplier. The second step is that in the operation of enterprise selecting the optimum logistics supplier from strategic supplier. Through the above-mentioned analysis, this paper propose the third party logistics supplier selection model on the basis of grey clustering and multi-objective decision-making with entropy right, employ grey clustering to classify suppliers with characteristic and advantage at first, select the excellent strategic suppliers, supplier qualified as the alternative supplier, do not consider non-qualified supplier. Then employ multi-objective decision-making with entropy right to quantize and sequence the strategic suppliers [7], [8].

\section{GREY CLUSTERING OF WHITENING WEIGHING FUNCTIONS}

\section{A. Set up Coefficient Matrix}

Suppose there is s clustering target, i.e. s projects of supplier selection; each project has $\mathrm{m}$ clustering index; $\mathrm{N}$ different grey clustering, $d_{i j}$ is whighing weighed value for NO. $i$ clustering target to NO. $j$ clustering index $(i=1,2,3, \cdots, s ; j=1,2,3, \cdots m)$,D is the matrix which is made up of the element $d_{i j}$, is called coefficient matrix:

$$
D=\left[\begin{array}{cccc}
d_{11} & d_{12} & \cdots & d_{1 m} \\
d_{21} & d_{22} & \cdots & d_{2 m} \\
\cdots & \cdots & \cdots & \cdots \\
d_{s 1} & d_{s 2} & \cdots & d_{s m}
\end{array}\right]
$$

\section{B. Determine Grey Whitening Weighed Function of Each Index $f_{i j}$}

Generally speaking, whitening weighed function is divided into three kinds, its function image and concrete expression formula is shown in Fig. 1:
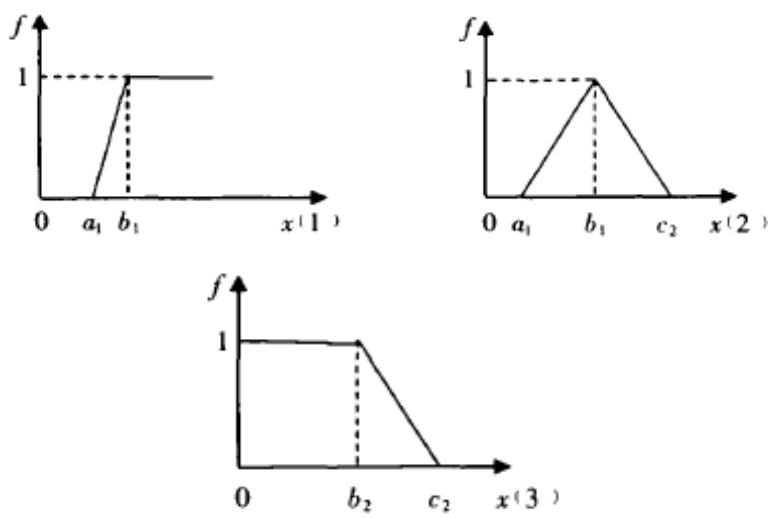

Fig. 1. Three kind whitening weighed function.

It is the described separately above three kinds whitening weighed function:

$$
f^{1}:\left[a_{1}, b_{1}, \infty\right], f^{2}:\left[a_{1}, b_{1}, c_{2}\right], f^{3}:\left[0, b_{2}, c_{2}\right]
$$

$$
\begin{gathered}
f^{1}(x)=\left\{\begin{array}{cc}
0, & x<a \\
x-a_{1} / b_{1}-a_{1}, & x \in\left[a_{1}, b_{1}\right] \\
1, & a \geq b_{1}
\end{array}\right. \\
f^{2}(x)=\left\{\begin{array}{cc}
0, & x \notin\left[a_{1}, c_{2}\right] \\
x-a_{1} / b_{1}-a_{1} & x \in\left[a_{1}, b_{1}\right] \\
c_{2}-x / c_{2}-b_{1} & x \in\left[b_{1}, c_{2}\right]
\end{array}\right. \\
f^{3}(x)=\left\{\begin{array}{cc}
0 & x \notin\left[0, c_{2}\right] \\
1 & x \in\left[0, b_{2}\right] \\
c_{2}-x / c_{2}-b_{2} & x \in\left[b_{1}, c_{2}\right]
\end{array}\right.
\end{gathered}
$$

C. Calculate Clustering Weighed Matrix

$$
\omega_{j k}=\lambda_{j k} / \sum_{j=1}^{m} \lambda_{j k}
$$

$\omega_{j k}$ is known as NO. grey clustering weigh of $j$ index, $\lambda_{j k}$ is NO. $k$ grey clustering critical value of $\mathrm{j}$ index. in this equitation

$$
\lambda_{j k}=\left\{\begin{array}{cc}
1 / 2\left(b_{1}+b_{2}\right), & f_{j k}=f^{0}:\left[a_{1}, b_{1}, b_{2}, c_{2}\right] \\
b_{1}, & f_{j k}=f^{1}:\left[a_{1}, b_{1}, \infty\right] \\
b_{1}, & f_{j k}=f^{2}:\left[a_{1}, b_{1}, c_{2}\right] \\
b_{1}, & f_{j k}=f^{3}:\left[0, b_{2}, c_{2}\right]
\end{array}\right.
$$

\section{Ask Clustering Coefficient and Carry on Clustering}

$$
\sigma_{i k}=\sum_{j=1}^{m} f_{j k}\left(d_{i j}\right) \omega_{j k}, \sigma_{i k} \text { is clustering coefficient that }
$$

NO.i clustering target correspond to NO.k grey clustering.

$$
\begin{aligned}
& \text { If there is } \sigma^{*}{ }_{i k} \text { satisfy } \\
& \sigma^{*}{ }_{i k}=\max \sigma_{i k}=\max \left\{\sigma_{i 1}, \sigma_{i 2}, \cdots, \sigma_{i k}\right\} \text { thus clustering }
\end{aligned}
$$

target $\mathrm{i}$ belong to grey clustering $k^{*}$.

\section{Sequence Alternative Supplier Based on Multi-ObJective Decision-MAKING WITH ENTROPY WEIGHT}

Through clustering analysis, we have selected strategic suppliers which meet customer's logistics requirement, suppose this kind has s suppliers, now the problem is turned into $\{n, s\}$ evaluation question. Multi-objective decision-making with entropy right is a kind of model which is applied in the case of only have judgement matrix and not have expert weight. Its essence is double basic point, because has carried on standardized treatment to the evaluation index at first, and makes negative ideal point become zero point. Sequence the strategic supplier through calculating the distance and proximity degree between the supplier and ideal point, in order to meet the customer's 
logistics demand. Algorithm of multi-objective decision-making with entropy weight is as follows:

Suppose the ideal point is $p^{*}=\left(p_{1}{ }^{*}, p_{2}{ }^{*}, \cdots, p_{m}{ }^{*}\right)^{T}$, in this equitation: $p_{i}{ }^{*}=\max \left\{a_{i j} \mid j=1,2, \cdots s ; i=1,2, \cdots m\right\}$;

Negative ideal point is standard matrix with entropy right.

$$
p \times=(0,0, \cdots 0)^{T} . A=\left[\begin{array}{ccc}
a_{11} & \cdots & a_{1 s} \\
\cdots & \cdots & \cdots \\
a_{m 1} & \cdots & a_{m s}
\end{array}\right]
$$

The distance between the logistics supplier evaluated and ideal point $p^{*}$

$$
d_{j}^{*}=\sqrt{\sum_{i=1}^{m}\left(a_{i j}-p_{i}^{*}\right)^{2}}, \quad j=1,2, \cdots s
$$

Proximity degree between the logistics supplier evaluated and ideal point is

$$
T_{j}=\frac{\left(p^{*}-0_{j}\right)^{T}\left(p^{*}-p^{*}\right)}{\left\|p^{*}-p *\right\|}=1-\frac{\sum_{j=1}^{m} a_{i j} p_{i}{ }^{*}}{\sum\left(p_{i}^{*}\right)^{2}}
$$

In this equitation $0_{j}=\left(a_{1 j}, a_{2 j}, \cdots a_{m j}\right)^{T}, T_{j} \in[0.1]$,

When calculating the weight, the decision information of each index is expressed with entropy value $e_{i}$,

$$
e_{i}=-k \sum_{j=1}^{S} a_{i j} \operatorname{In} x_{i j}, \text { in this } k=1 / \operatorname{Ins}, \text { Once confirm }
$$

the quantity of evaluation supplier $\mathrm{k}$ is constant value. Weight factor of No. i index is expressed with entropy weight degree

$$
\omega_{i}=d_{i} / \sum_{i=1}^{m} d_{i}
$$

Sequence the logistics supplier according to $T_{j}$ value (values low first). Adopting this method can realize sequencing to each strategic supplier which offers the theoretical foundation to enterprise policy-makers.

\section{ExAmPle}

\section{A. Select Strategic Supplier with Grey Clustering}

Now an enterprise is evaluating 20 the third party logistics supplier and selecting strategic supplier (excellent), alternative supplier (qualified) and non-qualified. the enterprise evaluate those suppliers in term of four great aspect such as price, service quality, service ability and hardware index. when evaluating, we compare every two supplier and score these supplier excellent supplier get 1 score, weak supplier and equal supplier get 0 score. on the basis of this ,apply grey clustering to evaluate those supplier, evaluation type is excellent, qualified and non-qualified. then select excellent supplier as strategic supplier, for calculating simpler, we set a example of select 4 supplier.

clustering unit: $i=1$, supplier $1 ; i=2$, supplier $2 ; i=3$, supplier $3 ; i=4$, supplier 4 .

1) Clustering project: $j=1$, price; $j=2$, service quality; $j=3$, service ability, $j=4$, hardware index.

2) Evaluation grey clustering: $k=1$, strategic supplier, $k=2$, qualified supplier; $k=3$, non-qualified supplier.

3) Suppose $d_{i j}$ signify sample which i unit correspond to $j$ project. Evaluation index matrix of four suppliers D is:

$$
D=\left[\begin{array}{llll}
d_{11} & d_{12} & d_{13} & d_{14} \\
d_{21} & d_{22} & d_{23} & d_{24} \\
d_{31} & d_{32} & d_{33} & d_{34} \\
d_{41} & d_{42} & d_{43} & d_{44}
\end{array}\right]=\left[\begin{array}{cccc}
15 & 18 & 17 & 18 \\
9 & 0 & 7 & 14 \\
10 & 12 & 10 & 22 \\
3 & 13 & 10 & 7
\end{array}\right]
$$

Determine whitening weight function of No. $j$ index in No. $k$ clustering use trigonometric whitening evaluation, appoint it as $f_{k j}(x)$, because of space limitation, we don't list three king grey clustering whitening functions now we ask clustering weight, the weight which No. $k$ index correspond to No. $k$ clustering is:

$$
\omega_{j k}=\lambda_{j k} / \sum_{j=1}^{m} \lambda_{j k}
$$

After calculated we can get:

$$
\begin{array}{cccc}
\text { When } k=1 & \omega_{11}=0.22 & \omega_{21}=0.26 & \omega_{31}=0.23 \\
\omega_{41}=0.29 & & & \\
\text { When } k=2 & \omega_{12}=0.21 & \omega_{22}=0.26 & \omega_{32}=0.23 \\
\omega_{42}=0.30 & & & \\
\text { When } k=3 & \omega_{13}=0.20 & \omega_{23}=0.24 & \omega_{33}=0.24 \\
\omega_{43}=0.32 & & &
\end{array}
$$

Grey coefficient which No. $k$ supplier belong to $k$ clustering is: $\sigma_{i k}=\sum_{j=1}^{m} f_{j k}\left(d_{i j}\right) \omega_{j k}$,

After calculated we can get:

When $i=1 \max _{1 \leq k \leq 3}\left\{\sigma_{1 k}\right\}=\sigma_{11}=0.901$, indicate supplier

1 belong to strategic supplier

When $i=2 \max _{1 \leq k \leq 3}\left\{\sigma_{2 k}\right\}=\sigma_{23}=0.486$, indicate supplier 2 belong to non-qualified supplier

When $i=3 \quad \max _{1 \leq k \leq 3}\left\{\sigma_{3 k}\right\}=\sigma_{32}=0.516$, indicate supplier 3 belong to qualified supplier

When $i=4 \max _{1 \leq k \leq 3}\left\{\sigma_{4 k}\right\}=\sigma_{43}=0.568$, indicate supplier 4 belong to non-qualified supplier

At last, there are 3 suppliers are excellent, we appoint them as strategic supplier and establish a kind of long-term collaboration relationship with them. There are 7 suppliers is qualified suppliers, we appoint them as alternative supplier, enterprise may help and advise them in preparation for the future under different strategic demands.

\section{B. Sequence the Strategic Supplier}

We have already got three strategic suppliers through the calculation above, if it is No. 1, No. 5 and No. 9 supplier, 
these three suppliers can meet logistics service demand finer. Now apply multi-objective decision-making with entropy right to elect the optimum supplier.

In this sequencing, because has already narrowed the range of calculating through preceding sorting out, now in order to get the more accurate data, specially elect six concrete index, such as fixed price, the rate of accuracy, the proportion in good condition, facilities, scale, informationization. Normalize the three suppliers evaluation index, we can get standard evaluation matrix.

$$
B=\left[\begin{array}{ccccccc}
0.4 & 0.2 & 0.5 & 0 & 1 & 0.4 \\
0 & 0 & 1 & 0.5 & 0 & 1 \\
1 & 1 & 0 & 1 & 1 & 0
\end{array}\right]
$$

After calculate index entropy and entropy weight, attribute matrix $H$ is

$$
H=\left[\begin{array}{cccccc}
0.2178 & 0.0820 & 0.2897 & 0 & 0.6322 & 0.2529 \\
0 & 0 & 0.5794 & 0.2897 & 0 & 0.6322 \\
0.5445 & 0.4101 & 0 & 0.5794 & 0.6322 & 0
\end{array}\right]
$$

From the above matrix get ideal point $P^{*}=(0.5445,0.4101,0.5794,0.5794,0.6322,0.6322)^{T}$, use formula (1) and (2)

Get rank of the distance and proximity of supplier evaluation ideal point is shown in Table I:

TABLE I: SUPPLIERS RANK

\begin{tabular}{cccc}
\hline supplier & NO.1 & NO.5 & NO.9 \\
\hline distance & 0.882 & 0.09738 & 0.8575 \\
$\begin{array}{c}\text { distance rank } \\
\text { proximity } \\
\text { proximity } \\
\text { rank }\end{array}$ & 2 & 3 & 1 \\
\hline
\end{tabular}

According to the result of calculation above, the supplier No. 9 is elected as the third party logistics supplier finally.

\section{CONCLUSION}

The third party logistics supplier selection is the basis that enterprises apply supply chain management, and is key factor in the outsourcing business. The paper confirms index and method of the third party logistics supplier selection according to the characteristic of the third party logistics supplier selection. Set up evaluation model of the third party logistics supplier selection based on grey clustering and multi-objective decision-making with entropy weight. In the course of selection of the third party logistics supplier, the first job is that classify all the third party logistics supplier using grey clustering, select strategic supplier, on the basis of this, using multi-objective decision-making with entropy weight, determine the distance and proximity degree of the supplier and get the rank of the strategic suppliers, which can offer support to enterprise decision.

\section{REFERENCES}

[1] S. H. Ma and Y. Lin, Supply Chain Management, Mechanic press, Beijing, 2000, ch. 1. pp. 5-7.

[2] H. X. Zou, Supply Chain Logistics Management, Qinghua University press, Beijing, 2000, ch. 1. pp. 2-3.

[3] W. K. Zhou and W. Ch. Jiang, "Supplier selection method based on improved topsis," System Engineering, pp. 39-44, July 2005.

[4] X. Liu and H. Y. Li, "The study on the model of supplier selection," China Management Science, pp. 12-14, June, 2005.

[5] J. N. Dun, Grey Prediction and Decision, Huazhong Technology Press, wuhan 2000, ch. 2. pp. 55-57.

[6] J. F. Dong and G. Wang, "The third party logistics supplier selection evaluation model based on entropy weight," Computer Engineering and Applications, pp. 21-24, Sep. 2007.

[7] T. Luo, "Optimization grey mode," Chinese Academy of Engineering, pp. 35-36, Jan. 2007.

[8] Y. Tian, "Study on supplier selection of logistics service supply chain in the chain construction," Systems Engineering Theory \& Practice, pp. 45-47, May 2003.

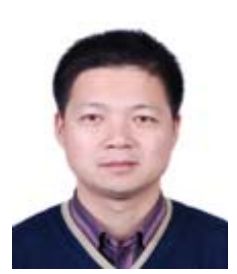

Yewang Zhou was born in Hubei Province, China in 1974. He was graduated from School of Transportation, Wuhan University of Technology. His main subject of research is focused on intelligent control and computer application technology.

He is an associate professor of School of Business, Huanggang Normal University. 